\title{
HARNESSING AND STORING SOLAR THERMAL ENERGY USING PHASE CHANGE MATERIAL (PCM) IN A SMALL FLAT PLATE COLLECTOR
}

\author{
Sathish K. Gurupatham ${ }^{1, *}$, G.K Manikandan², Fahad Fahad ${ }^{1}$
}

\begin{abstract}
Recently, the initiative to bring down the continuous increase in the level of greenhouse gas emissions has widely spread in many countries not only because of the stringent emission norms but also the rising fuel prices which have led to utilize renewable energy sources, more. When it comes to the different forms of renewable energy available, solar energy is considered to be the best option due to its abundant availability in nature. Still, there are a few hurdles to first get over when dealing with solar energy. For instance, the lack of effective technology has caused solar energy to be a costly endeavor and there are issues involved in the process of conversion of solar energy into useful forms of energy. Due to the recent developments in technology, the application of phase change materials (PCM) has become an attractive method to store solar energy. Among various sugar alcohols, Erythritol is the one which is higher in latent heat, more thermally stable, non-toxic, inexpensive, and easily available. In this paper, the phase change material, Erythritol $\left(\mathrm{C}_{4} \mathrm{H}_{8} \mathrm{O}_{4}\right)$ is utilized to harness the solar energy and a novel method of transporting the solar energy from the location it was harnessed to a location where it can be utilized is also shown. The variation in the rate at which the solar energy is harnessed is also shown on five different days when the direct solar radiation was high and low on the location of experiment. Keywords: solar radiation, phase change material (PCM), solar energy.
\end{abstract}

Keywords: Phase Change Material, Latent Heat, Solar Energy

\section{INTRODUCTION}

Recently, many nations in the world have turned their attention towards the utilization of renewable sources of energy such as solar, wind, geothermal, tidal, biogas etc. Solar energy is a major renewable source of especially among countries with a tropical climate. These countries are utilizing non-imaging and imaging concentrators in order to harness this solar energy through radiation and convert it into thermal energy. The investigations into storing thermal energy effectively gained more attention beginning with the energy crisis (1973-1974) when many countries turned to utilizing non-conventional energy sources [1]. The results obtained from these investigations have been published in many research papers and academic books such as Schaetzle [1], Schmidt [2], Beckmann and Gill [3], Garg et al. [4] and Garg [5]. General principles and various technologies for solar energy storage were summarized by Garg et al. [4]. Traditionally, energy was stored in the form of sensible heat which requires large volume storage material. The storage volume can be significantly reduced if energy is stored in the form of latent heat, and thus can benefit plenty of applications [6].

The sensible and latent heat storage can be achieved employing the appropriate phase change materials (PCM) Murat Kenisarin et al. [7]. Using PCM for thermal energy storage provides a feasible solution to increase the efficiency of the storage and use of energy in many domestic and industrial sectors Atul Sharma et al. [8]. A great number of scientific publications and patents on latent heat storage for solar energy conservation stimulated the appearance of Lane's monograph [9,10]. Dincer and Rosen [11] came up with another monograph to address the problems of thermal energy storage. Schroder J and Gawron K. [12] have described the following phase change material (PCM) properties as desirable for latent heat storage:

1. A high value of the heat of fusion and specific heat per unit volume and weight,

2. A melting point which matches the application,

3. Low vapor pressure at the operational temperature,

4. Chemical stability and non-corrosiveness

5. PCM should not be hazardous, highly inflammable or poisonous

6. PCM should have a reproducible crystallization without degradation

7. PCM should have a small super-cooling degree and a high rate of crystal growth

8. PCM should have a small volume variation during solidification 
9. High thermal conductivity

10. PCM should be of abundant supply and at a low cost

Liwu Fan et al. [13] have concluded that a PCM should possess high thermal conductivity for efficient heat transfer with congruent phase-change behavior to avoid irreversible separation of their constituents. During the development of PCM, many different groups of materials have been studied, including inorganic compounds (salt and salt hydrates) [14], organic compounds such as paraffin's [15], fatty acids [16] and even polymeric materials such as Polyethylene glycol (PEG) and the relationship between the fundamental structures.

Francis Agyenim et al. [17] have reviewed the heat transfer and phase change problem formulation for latent heat thermal energy storage systems. Kinga Pielichowska et al. [18] have carried out a work on the review of different phase change materials and their specifications. The selection of the PCM, Erythritol $(\mathrm{MgCl} 26 \mathrm{H} 2 \mathrm{O})$ for the present work has been identified for applications ranging in temperature from $80^{\circ} \mathrm{C}$ to $1400 \mathrm{C}$. For high- temperature applications beyond 750 0C, Mgcl2 can be used Weihuan Zhao et al. [19]

Several endeavors of research have investigated the application of PCM in domestic water heating [20, 21]. M.K. Anuar Sharif et al. [22] have reviewed the application of a PCM in domestic hot water systems in which the PCM is inserted at various positions in a solar flat plate collector below the tubes, covering half the perimeter of the tubes, while immersing the tubes in the PCM with and without reflectors. [23, 24 \& 25]

Abdul Jabbar N et al. [26] have compared the thermal performance of a DHW (Domestic Hot Water) system with a PCM and the same with a conventional DHW system.

Due to the fact that India lies in the Torrid Zone, it is gifted with solar radiation for 270 days in a year. The annual average irradiation ranges from a low value of $4.4 \mathrm{KWh} / \mathrm{m}^{2}$ to a high value of $6.6 \mathrm{KWh} / \mathrm{m}^{2}$. India has abundant solar irradiation, with an annual average intensity of 200 MW/Sq.km radiations occurring on a geographical area of 3.287 million km square area which accounts for 657.4 million MW a year. Hence, a solar thermal technology employing a PCM can store thermal energy in a remote place during the daytime and further transport it to the industries during the hours when the sun does not shine (night time). Industries that do have sufficient space to install the solar thermal systems, do not find any hurdles in practicing them except for thermal energy storage, which is still under research. On the other hand, most of the industries either in a metropolitan city or elsewhere do not have sufficient space to install such systems that require vast land area.

Hence in the present work, we have attempted to overcome such a constraint by harnessing solar energy in a prototype flat plate collector, which involves storing the solar energy in a phase change material and transporting it from one location to another and then transferring the energy to heat water at ambient temperature. The phase change material, Erythritol is utilized in order to store the solar thermal energy and extract it in the evening hours especially for the industries which are located in cities where space is the primary limitation to have larger solar energy harvesting units.

\section{EXPERIMENTAL SET-UP}

A prototype flat plate collector of size $420 \mathrm{~mm} \times 320 \mathrm{~mm}$ was fabricated using waterproof plywood of thickness $12 \mathrm{~mm}$ with a surface area of $0.1344 \mathrm{~m} 2$ for the experimental investigation. Six copper pipes of diameter $12.5 \mathrm{~mm}$ and length $360 \mathrm{~mm}$ were placed inside the flat plate collector on a 22gauge copper sheet of dimension $600 \mathrm{~mm} \times 340 \mathrm{~mm}$ and fastened using copper binding wires. A single glazing with a thickness of $4 \mathrm{~mm}$ covers the top surface of the collector. The sides and the bottom surface of the collector were insulated with glass wool to prevent the heat loss. The entire setup was mounted on a metal frame with one side inclined at 160 . Copper pipes were filled with the phase change material (Erythritol). Thermocouples of ' $K$ ' type (10 no's) with a digital indicator were used to measure the temperature of the PCM at regular intervals.

Prior to the investigation, the thermocouples were calibrated by placing them at two fixed points namely ice and boiling water. The melting temperature of the PCM was confirmed by testing a sample in the laboratory. Next, the prototype flat plate collector incorporating the PCM copper tubes were placed in a non-shadow area facing south. The investigation was carried out for five days, recording the temperature of the PCM at regular 60- minute intervals. Once the PCM reached a temperature of $140^{\circ} \mathrm{C}$, the investigation was stopped, and all the absorber pipes were removed from the collector and placed in an insulated tank containing water of one liter at mbient temperature. Polyurethane foam insulation (PUF) was used as insulating material to prevent the heat transfer to keep the PCM in the molten state. 


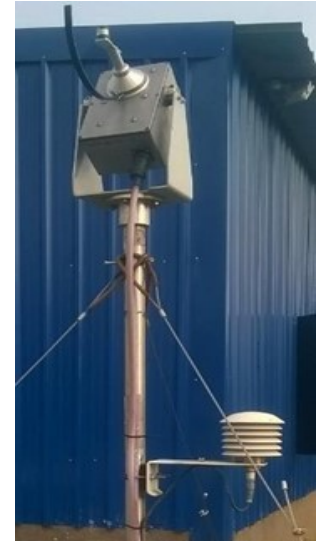

(a)

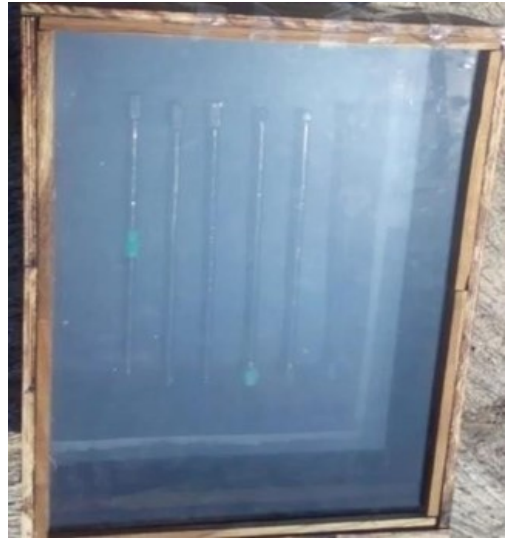

(b)

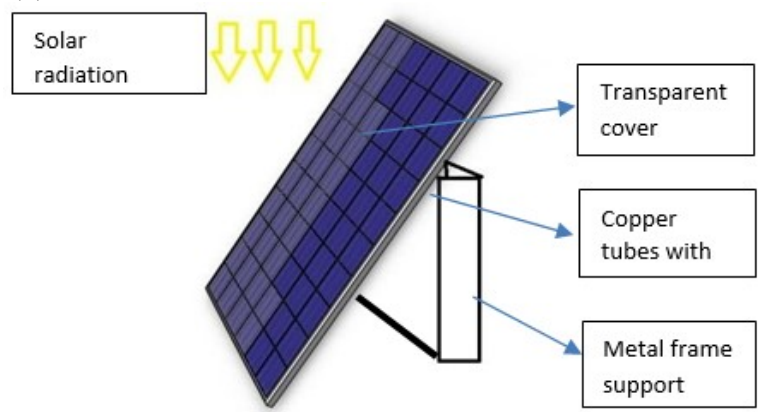

(c)

Figure 1. (a) pyranometer, (b) copper tubes encapsulating Erythritol (PCM) and (c) configuration diagram

Experiments were conducted on 5 different days. A pyranometer (CSP Services) was used to measure the radiation data at 15 -minute interval starting from 9.00 a.m. The measured radiation data for 5 days, which included two days in February and three days in March, are given in the following table. The average value of the data for a given day was then used for the theoretical calculations.

Table 1. Solar radiation data recorded on different days

\begin{tabular}{|c|c|c|c|c|c|}
\hline Time & $\begin{array}{c}\text { 01-03-2017 } \\
\text { Direct } \\
\text { radiation } \\
\mathrm{W} / \mathrm{m}^{2}\end{array}$ & $\begin{array}{c}\text { 02-03-2017 } \\
\text { Direct } \\
\text { radiation } \\
\mathrm{W} / \mathrm{m}^{2}\end{array}$ & $\begin{array}{c}03-03-2017 \\
\text { Direct radiation } \\
\mathrm{W} / \mathrm{m}^{2}\end{array}$ & $\begin{array}{c}01-02-2017 \\
\text { Direct radiation } \\
\mathrm{W} / \mathrm{m}^{2}\end{array}$ & $\begin{array}{c}\text { 02-02-2017 } \\
\text { Direct radiation } \\
\mathrm{W} / \mathrm{m}^{2}\end{array}$ \\
\hline $09: 00$ & 9.38 & 516.98 & 637.89 & 2.53 & 311.29 \\
\hline $09: 15$ & 606.16 & 562.83 & 694.31 & 28.96 & 123.31 \\
\hline $09: 30$ & 8.27 & 437.59 & 658.01 & 0.744 & 227.50 \\
\hline $09: 45$ & 628.24 & 303.24 & 738.53 & 0.003 & 382.29 \\
\hline $10: 00$ & 666.57 & 582.53 & 720.85 & 0.20 & 295.07 \\
\hline $10: 15$ & 592.76 & 594.59 & 761.28 & 2.279 & 5.99 \\
\hline $10: 30$ & 472.17 & 616.48 & 747.48 & 4.38 & 2.69 \\
\hline $10: 45$ & 646.26 & 651.30 & 724.09 & 8.42 & 2.47 \\
\hline $11: 00$ & 667.59 & 666.12 & 708.72 & 10.87 & 5.14 \\
\hline $11: 15$ & 461.36 & 515.62 & 749.32 & 8.01 & 1.53 \\
\hline $11: 30$ & 671.85 & 709.43 & 745.88 & 23.91 & 8.49 \\
\hline $1: 45$ & 444.13 & 579.51 & 845.05 & 5.87 & 8.06 \\
\hline $12: 00$ & 743.71 & 1.03 & 842.3 & 5.32 & 34.76 \\
\hline $12: 15$ & 42.46 & 785.35 & 806.83 & 17.11 & 171.13 \\
\hline $12: 30$ & 2.19 & 784.37 & 799.43 & 409.27 & 2.13 \\
\hline $12: 45$ & 696.90 & 757.56 & 783.30 & 586.19 & 500.07 \\
\hline $13: 00$ & 615.86 & 186.83 & 793.13 & 559.74 & 296.60 \\
\hline Average & $\mathbf{4 6 7 . 4 6}$ & $\mathbf{5 1 1 . 2 6}$ & $\mathbf{7 6 1 . 2 9}$ & $\mathbf{7 7 . 2 1}$ & $\mathbf{1 0 4 . 2 2}$ \\
\hline
\end{tabular}




\section{Design of Prototype Flat Plate Collector (PTFP)}

$\begin{array}{ll}\text { Aperture area of flat plate collector }\left(\mathrm{A}_{\mathrm{c}}\right) & =0.260 \mathrm{~m}^{2} \text { Volume of each copper pipe }(\mathrm{V}) \quad=5.30 \times 10-5 \mathrm{~m}^{3} \\ \text { Density of the PCM }(\rho) & =1450 \mathrm{~kg} / \mathrm{m}^{3} \\ \text { Mass of the PCM in each copper } & =0.076 \mathrm{~kg}\end{array}$

\section{Energy Incident on the Prototype Collector (Q)}

The heat energy incident on the collector area,

$$
Q=\eta_{\mathrm{o}} \times \mathrm{I}_{\mathrm{B}} \times \mathrm{A}_{\mathrm{c}}
$$

Where, $\eta_{\mathrm{o}}=$ optical efficiency of the collector in (\%)

$\mathrm{I}_{\mathrm{B}}=$ Beam irradiation of the Collector $\left(\mathrm{W} / \mathrm{m}^{2}\right)$

$=467.46 \mathrm{~W} / \mathrm{m}^{2}$

$\mathrm{A}=$ Area of the collector $\left(\mathrm{m}^{2}\right)$

Optical efficiency,

$$
\eta_{\mathrm{O}}=\alpha \times \tau=0.64
$$

Where, $\alpha=$ Absorptivity of the absorber copper plate (0.8)

$\tau=$ Transmissivity of glass $(0.8)$

Therefore, the energy incident on the prototype flat Plate collector is $Q=77.7866047 \mathrm{~W}(\mathrm{~J} / \mathrm{S})$

\section{Energy Required for The Fusion of the PCM (Q)}

The specific heat was considered as $2.9 \mathrm{KJ} / \mathrm{kg} / 0 \mathrm{C}$ for liquid state, $1.3 \mathrm{KJ} / \mathrm{kg} / 0 \mathrm{C}$ for solid state and the heat of fusion to be $340.6 \mathrm{KJ} / \mathrm{kg}$ whereas the melting temperature 119.50C for Erythritol [27].

$\mathrm{Q}=$ Heat collected duo to temperature rise in solid state + Heat of fusion + Heat accumulated duo to temperature rise in liquid state.

$$
\mathrm{Q}=\mathrm{mc}_{\mathrm{p} \text { (solid) }} \Delta \mathrm{T}+\mathrm{m} \mathrm{h}_{\mathrm{fg}}+\mathrm{mc}_{\mathrm{p} \text { (liquid) }} \Delta \mathrm{T}
$$

where, $\mathrm{m}$ is mass of the PCM in $\mathrm{kg}, \mathrm{c}_{\mathrm{p}}$ is specific heat capacity of the PCM at constant pressure, $\Delta \mathrm{T}$ is temperature gradient $\left({ }^{0} \mathrm{C}\right), \mathrm{h}_{\mathrm{fg}}$ is Latent heat of fusion of PCM

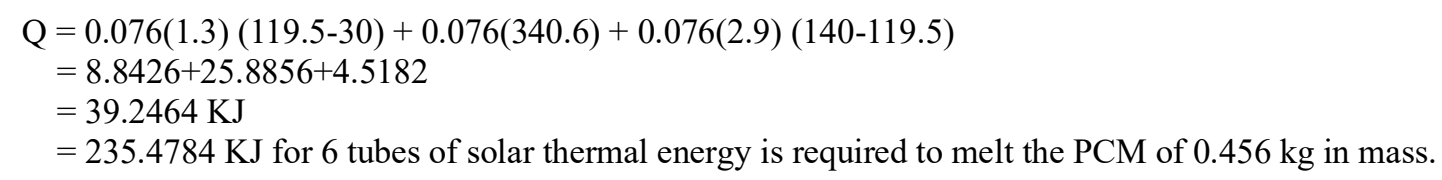

\section{Time Taken for Fusion of the PCM}

$$
t=Q / \dot{Q}
$$

where, $\mathrm{t}=$ time in minutes, $\mathrm{Q}$ is the total heat required for the fusion, $\dot{Q}$ is the rate of energy incident on the collector.

$\mathrm{t}=\left(235.48 \times 10^{3} \mathrm{~J} / 77.78 \times 60 \mathrm{~J} / \mathrm{min}\right)=51$ minutes

Therefore, the time taken for the fusion of the $\mathrm{PCM}=51$ minutes.

\section{RESULTS AND DISCUSSION}

The prototype flat plate collector with PCM incorporated tubes was tested on, March 01, March $02 \&$ March 3 and February $01 \&$ February 02 totaling a period of five days. The details of temperature attained by the PCM during the collection of solar energy process through the flat plate collector and the time taken to reach that temperature are tabulated and plotted below. The details of temperature measurement of the phase change material with respect to time on that specific day are recorded in the tables $02,03,04,05 \& 06$. The figures $2,3 \& 4$ show the variation in the time taken for the phase change material to melt and reach a temperature of $140^{\circ} \mathrm{C}$. It can be seen that depending on the intensity of the radiation on that specific day the time taken to reach this temperature $\left(140^{\circ} \mathrm{C}\right)$ 
changed. For instance, it took 70 minutes to reach $140^{\circ} \mathrm{C}$ on March 01 whereas it took just 35 minutes to reach the same temperature on March 03 since the radiation intensity was $467.46 \mathrm{~W} / \mathrm{m} 2$ on the former day whereas it was $761.29 \mathrm{~W} / \mathrm{m} 2$ on the latter day. It may also be noted that on March 2, it took 50 minutes which was in between these two days for the same reason. It is also observed that during the phase change of the material from solid to liquid the temperature did not change for a while since the heat transfer was utilized for the change of the phase of the material. This duration changed from day to day depending on the intensity of the solar radiation on that specific day.

In the similar fashion, the figures $6 \& 7$ show the variation in the time taken on the month of February to melt the same phase change material of the same quantity. The figures reveal that due to the less intensity of the radiation that was occurring during this month the time that was taken to melt the phase change material was even longer. It took almost five hours on February 1 where as it was four hours on February 02. Obviously, the reason for such a drastic variation was the lower magnitude of the solar radiation intensity on these days. It is also observed that the time taken to melt the phase change material closely matches the theoretical calculation that was performed above.

The energy that was harnessed totaling $235.47 \mathrm{KJ}$ per day in the form of sensible and latent heat by storing in the PCM can be utilized when the necessity arises. After the hot copper pipes were removed from the collector and they were placed in a well-insulated container with Polyurethane Foam (PUF) material to eliminate the heat transfer losses. These copper pipes can be stored in an insulated container and delivered to the location where energy is required. During the evening hours, the energy stored can be used for domestic heat applications such as heating of water. It is anticipated to have a $10 \%$ heat loss for 8 hours of storage, with PUF insulation around the container of PCM which leads to $212 \mathrm{KJ}$ of thermal energy will still be available, which is sufficient enough to raise the temperature of 1 litre of water from $30^{\circ}$ to $75^{\circ} \mathrm{C}$.

Table 2. The temperature of phase change material at different time intervals on March 1, 2017

\begin{tabular}{|c|c|c|c|c|c|c|c|}
\hline \multirow[b]{2}{*}{ Time } & \multicolumn{7}{|c|}{ Temperature $\left({ }^{\circ} \mathrm{C}\right)$} \\
\hline & \begin{tabular}{|l|l} 
T1 & \\
\end{tabular} & $\mathrm{T} 2$ & T3 & T4 & T5 & T6 & $\mathrm{T}_{\mathrm{Avg}}$ \\
\hline $10.00 \mathrm{am}$ & 30 & 29 & 29 & 30 & 31 & 31 & 30 \\
\hline $10.05 \mathrm{am}$ & 45 & 43 & 44 & 46 & 44 & 46 & 45 \\
\hline $10.10 \mathrm{am}$ & 60 & 59 & 59 & 60 & 61 & 60 & 60 \\
\hline $10.15 \mathrm{am}$ & 75 & 74 & 75 & 76 & 74 & 75 & 75 \\
\hline $10.20 \mathrm{am}$ & 95 & 94 & 95 & 93 & 94 & 96 & 95 \\
\hline $10.25 \mathrm{am}$ & 110 & 109 & 108 & 109 & 110 & 109 & 109 \\
\hline $10.35 \mathrm{am}$ & 121 & 122 & 120 & 122 & 119 & 119 & 120 \\
\hline $11.00 \mathrm{am}$ & 120 & 123 & 122 & 119 & 118 & 119 & 120 \\
\hline $11.10 \mathrm{am}$ & 140 & 142 & 141 & 140 & 141 & 140 & 140 \\
\hline
\end{tabular}

Table 3. The temperature of phase change material at different time intervals on March 2, 2017

\begin{tabular}{|c|c|c|c|c|c|c|c|}
\hline \multirow[t]{2}{*}{ Time } & \multicolumn{7}{|c|}{ Temperature (0C) } \\
\hline & $\mathrm{T} 1$ & $\mathrm{~T} 2$ & T3 & T4 & T5 & T6 & $\mathrm{T}_{\mathrm{Avg}}$ \\
\hline $10.00 \mathrm{am}$ & 30 & 29 & 29 & 28 & 30 & 30 & 29 \\
\hline $10.02 \mathrm{am}$ & 45 & 43 & 44 & 43 & 44 & 46 & 44 \\
\hline $10.04 \mathrm{am}$ & 60 & 61 & 60 & 62 & 61 & 60 & 61 \\
\hline $10.06 \mathrm{am}$ & 75 & 74 & 75 & 76 & 74 & 75 & 75 \\
\hline $10.08 \mathrm{am}$ & 92 & 91 & 92 & 91 & 89 & 80 & 91 \\
\hline $10.10 \mathrm{am}$ & 109 & 107 & 108 & 108 & 108 & 109 & 108 \\
\hline $10.15 \mathrm{am}$ & 121 & 119 & 119 & 118 & 119 & 119 & 119 \\
\hline $10.45 \mathrm{am}$ & 125 & 123 & 122 & 125 & 128 & 127 & 125 \\
\hline $10.50 \mathrm{am}$ & 140 & 139 & 141 & 140 & 139 & 140 & 140 \\
\hline
\end{tabular}


Journal of Thermal Engineering, Research Article, Vol. 6, No. 4, pp. 93-99, July, 2020

Table 4. The temperature of phase change material at different time intervals on March 3, 2017

\begin{tabular}{|c|c|c|c|c|c|c|c|}
\hline \multirow[t]{2}{*}{ Time } & \multicolumn{7}{|c|}{ Temperature $\left({ }^{0} \mathrm{C}\right)$} \\
\hline & $\mathrm{T} 1$ & $\mathrm{~T} 2$ & T3 & T4 & T5 & T6 & $\mathrm{T}_{\text {Avg }}$ \\
\hline $10.00 \mathrm{am}$ & 30 & 29 & 29 & 29 & 30 & 31 & 30 \\
\hline $10.01 \mathrm{am}$ & 45 & 44 & 45 & 44 & 43 & 44 & 44 \\
\hline $10.02 \mathrm{am}$ & 59 & 58 & 60 & 60 & 58 & 59 & 59 \\
\hline $10.03 \mathrm{am}$ & 72 & 71 & 71 & 73 & 72 & 72 & 72 \\
\hline $10.04 \mathrm{am}$ & 85 & 84 & 85 & 82 & 83 & 85 & 84 \\
\hline $10.05 \mathrm{am}$ & 98 & 97 & 97 & 96 & 96 & 97 & 97 \\
\hline $10.15 \mathrm{am}$ & 119 & 118 & 120 & 122 & 121 & 122 & 120 \\
\hline $10.25 \mathrm{am}$ & 118 & 119 & 120 & 121 & 121 & 121 & 120 \\
\hline $10.35 \mathrm{am}$ & 140 & 141 & 139 & 137 & 139 & 140 & 139 \\
\hline
\end{tabular}

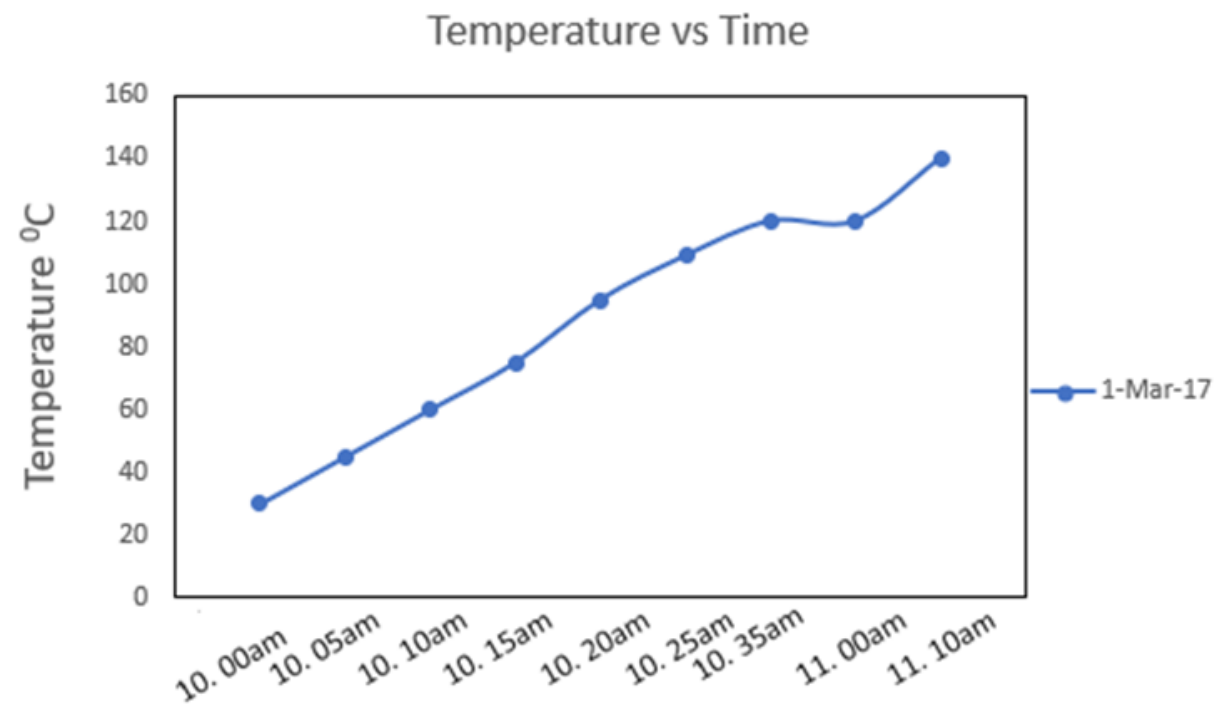

Figure 2. The recorded temperature $\mathrm{v}_{\mathrm{s}}$ time on March 01,2017

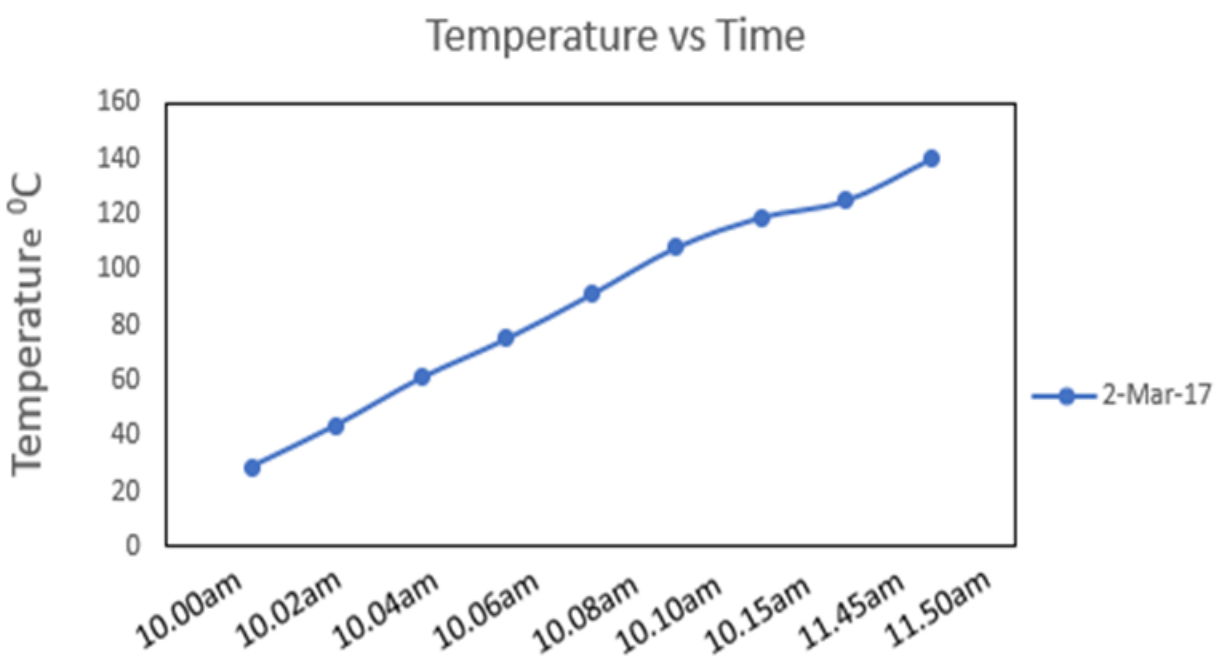

Figure 3. The recorded temperature $\mathrm{v}_{\mathrm{s}}$ time on March 02, 2017 


\section{Temperature vs Time}

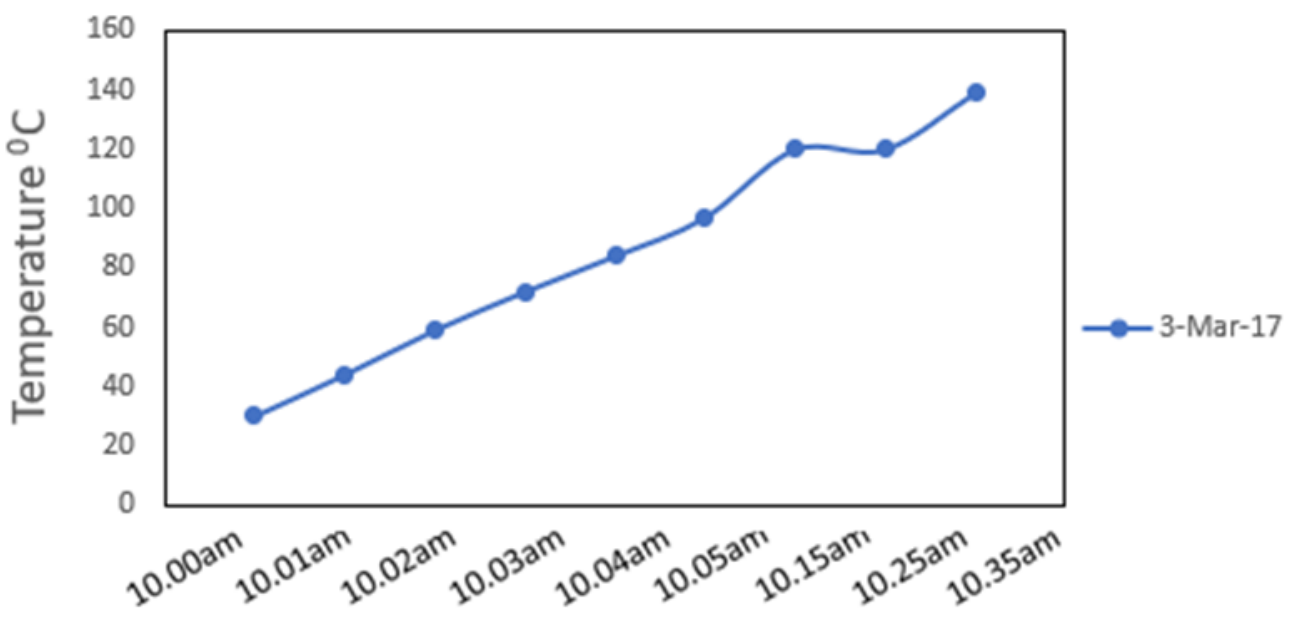

Figure 4. The recorded temperature $v_{s}$ time on March 03, 2017

Table 5. The temperature of phase change material at different time intervals on February 1, 2017

\begin{tabular}{|c|c|c|c|c|c|c|c|}
\hline \multirow[t]{2}{*}{ Time } & \multicolumn{7}{|c|}{ Temperature $\left({ }^{0} \mathrm{C}\right)$} \\
\hline & \begin{tabular}{|l|l} 
T1 & 11
\end{tabular} & $\mathrm{~T} 2$ & T3 & $\mathrm{T} 4$ & $\mathrm{~T} 5$ & T6 & $\mathrm{T}_{\text {Avg }}$ \\
\hline $10.00 \mathrm{am}$ & 30 & 29 & 29 & 29 & 30 & 31 & 30 \\
\hline $10.10 \mathrm{am}$ & 42 & 44 & 45 & 46 & 43 & 44 & 44 \\
\hline $10.20 \mathrm{am}$ & 59 & 58 & 60 & 61 & 58 & 59 & 59 \\
\hline $10.30 \mathrm{am}$ & 72 & 71 & 71 & 70 & 71 & 71 & 71 \\
\hline $10.40 \mathrm{am}$ & 85 & 84 & 85 & 84 & 83 & 85 & 84 \\
\hline $10.50 \mathrm{am}$ & 98 & 97 & 97 & 96 & 96 & 97 & 97 \\
\hline $11.00 \mathrm{am}$ & 115 & 114 & 114 & 115 & 116 & 115 & 115 \\
\hline $12.00 \mathrm{am}$ & 120 & 121 & 120 & 120 & 121 & 119 & 120 \\
\hline $1.00 \mathrm{am}$ & 121 & 120 & 120 & 121 & 119 & 120 & 120 \\
\hline $2.00 \mathrm{am}$ & 120 & 121 & 120 & 121 & 120 & 119 & 120 \\
\hline $2.30 \mathrm{am}$ & 131 & 131 & 130 & 131 & 130 & 132 & 131 \\
\hline $3.00 \mathrm{am}$ & 141 & 140 & 138 & 142 & 140 & 140 & 140 \\
\hline
\end{tabular}

Table 6. The temperature of phase change material at different time intervals on February 2, 2017

\begin{tabular}{|c|c|c|c|c|c|c|c|}
\hline \multirow[t]{2}{*}{ Time } & \multicolumn{7}{|c|}{ Temperature $\left({ }^{0} \mathrm{C}\right)$} \\
\hline & \begin{tabular}{|l|l} 
T1 & $\mathrm{T}_{2}^{2}$
\end{tabular} & & & $\mathrm{~T} 4$ & T5 & T6 & TAvg \\
\hline $10.00 \mathrm{am}$ & 30 & 29 & 28 & 29 & 30 & 31 & 30 \\
\hline $10.10 \mathrm{am}$ & 42 & 42 & 42 & 44 & 43 & 43 & 43 \\
\hline $10.20 \mathrm{am}$ & 58 & 57 & 58 & 58 & 57 & 59 & 58 \\
\hline $10.30 \mathrm{am}$ & 71 & 71 & 70 & 69 & 69 & 69 & 70 \\
\hline $10.40 \mathrm{am}$ & 80 & 81 & 80 & 79 & 79 & 80 & 80 \\
\hline $10.50 \mathrm{am}$ & 88 & 87 & 87 & 86 & 88 & 87 & 87 \\
\hline $11.00 \mathrm{am}$ & 95 & 96 & 94 & 95 & 94 & 95 & 95 \\
\hline $12.00 \mathrm{am}$ & 105 & 104 & 104 & 106 & 104 & 103 & 104 \\
\hline $1.00 \mathrm{am}$ & 117 & 116 & 115 & 117 & 118 & 119 & 117 \\
\hline $2.00 \mathrm{am}$ & 128 & 128 & 128 & 129 & 127 & 127 & 128 \\
\hline $2.30 \mathrm{am}$ & 140 & 141 & 139 & 138 & 139 & 140 & 140 \\
\hline
\end{tabular}




\section{Temperature vs Time}

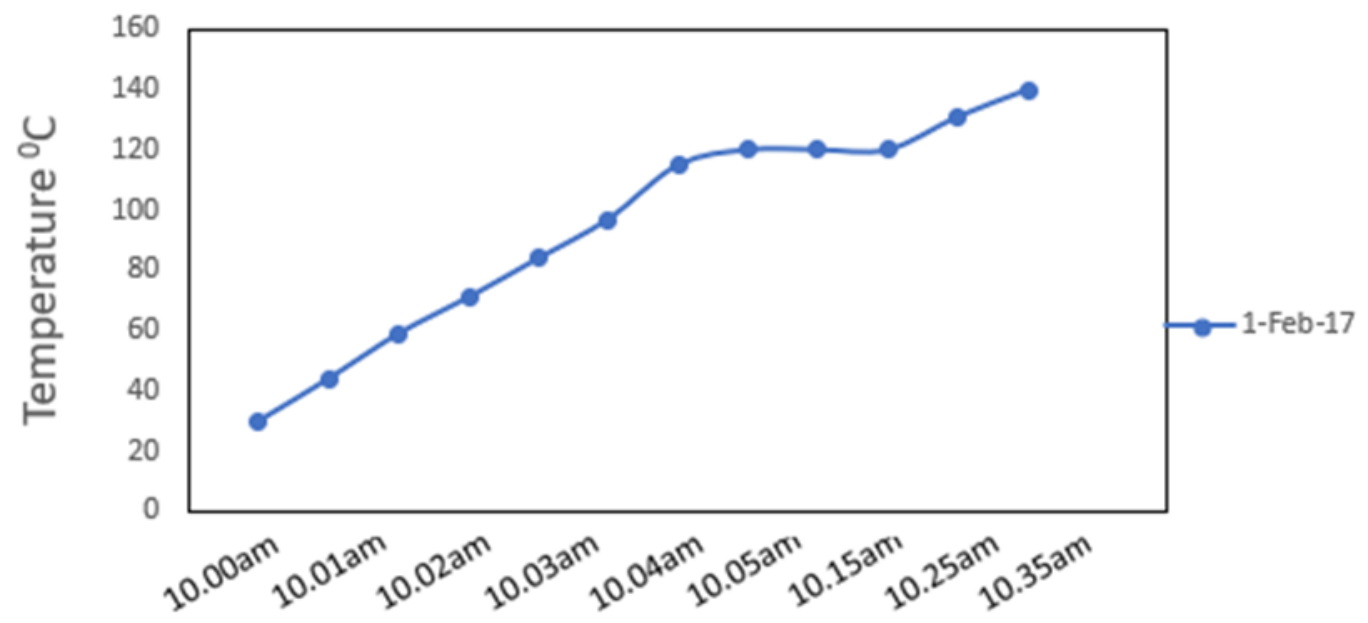

Figure 5. The recorded temperature vs time on February 01, 2017

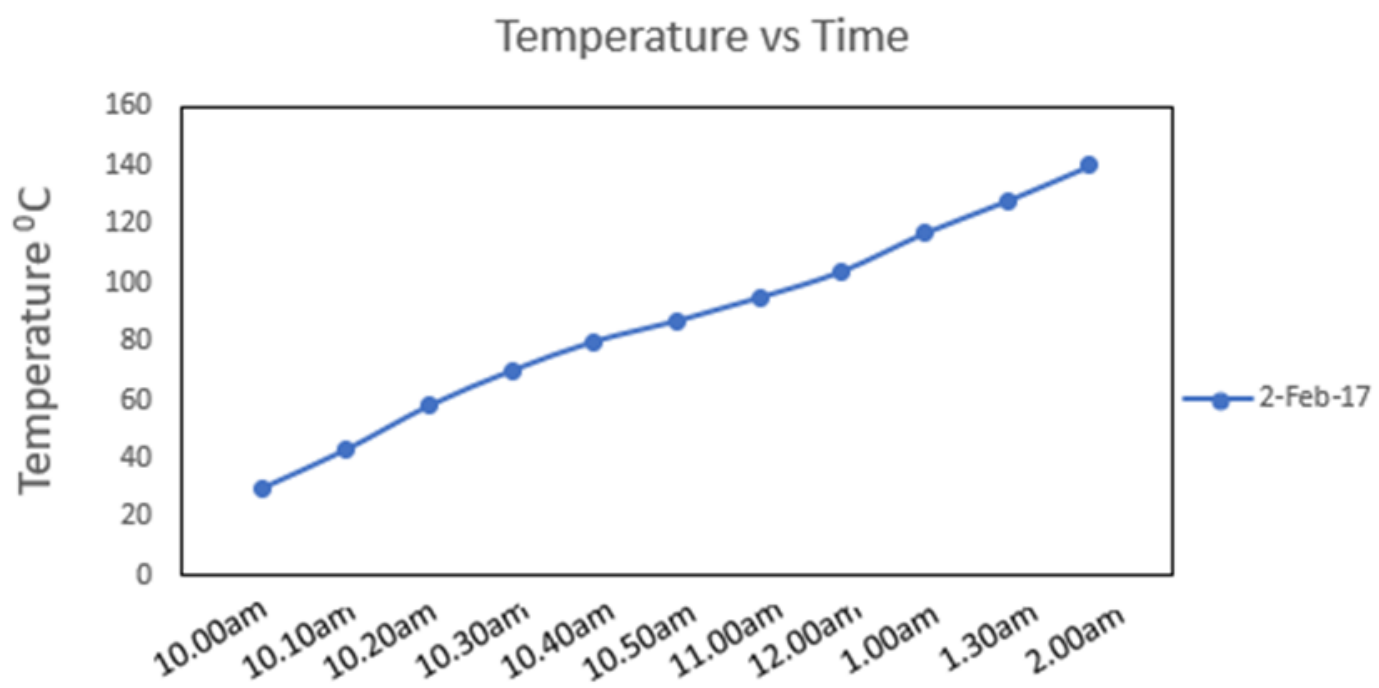

Figure 6. The recorded temperature vs time on February 02, 2017

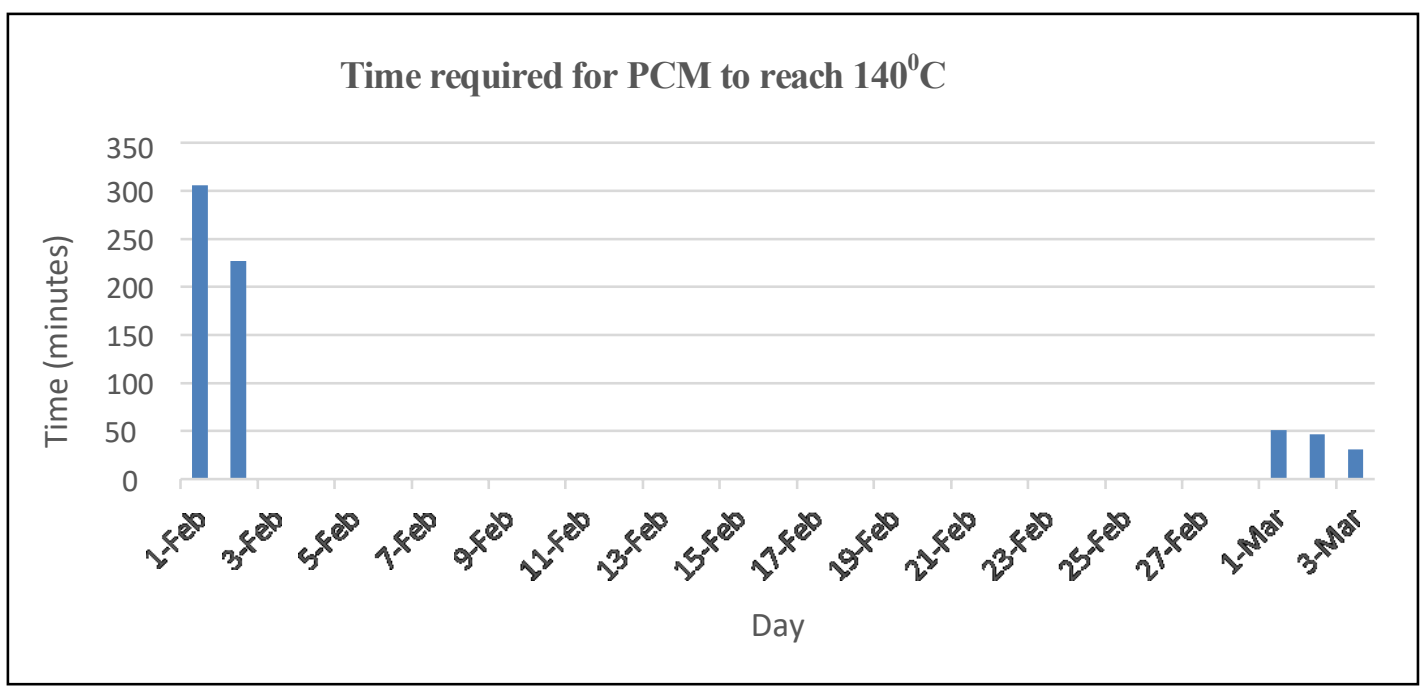

Figure 7. Time required for the PCM to reach the target temperature $\left(140^{\circ} \mathrm{C}\right)$ on five 


\section{CONCLUSION}

On experimental investigation of a prototype flat plate collector incorporating the PCM(Erythritol), it is clearly shown that the solar energy can be harnessed and stored in the phase changing material in the form of latent and sensible heat which can be retrieved for later usage. It is observed that the energy harnessed and stored will be sufficient enough to raise the temperature of one litre of water by $45^{\circ} \mathrm{C}$ from the ambient temperature. The time taken to store the required energy was observed to be 51 minutes when sufficient solar radiation is present. Space thus occupied by this set up is just $0.256 \mathrm{~m} 2$. Thus, increasing the size of the collector and refurbishing the model by incorporating more pipes within the given area, one could harness and store energy that is sufficient enough to deliver heat energy for cooking application for a single family in the evening hours.

The novelty of this work lies in transporting the energy from a location where it is harnessed and delivering it to the place where it is utilized. On a large scale, this work will be fruitful to deliver the solar thermal energy to industries by transporting the PCM incorporated pipes in a well-insulated container.

In the not too distant future, the feasibility of other concentrated thermal systems such as parabolic trough collector, linear Fresnel or dish collector could be experimentally investigated. Thus, the non-availability of space in industries for the installation of solar thermal systems can be overcome by installing the systems in remote locations and transporting and delivering the energy required for the industries and even for domestic applications.

\section{NOMENCLATURE}

$\begin{array}{ll}\mathrm{C}_{\mathrm{p}} & \text { Specific heat, } \mathrm{kJ} / \mathrm{kg}{ }^{\circ} \mathrm{C} \\ m & \text { mass, } \mathrm{kg} \\ Q & \text { Heat, } \mathrm{kJ} \\ t & \text { Time, } \mathrm{sec} \\ \mathrm{h}_{\mathrm{fg}} & \text { Latent heat, } \mathrm{kJ} / \mathrm{kg} \\ T & \text { Temperature, }{ }^{\circ} \mathrm{C} \\ \mathrm{Ac} & \text { Collector area, } \mathrm{m}^{2} \\ \mathrm{I} & \text { Beam irradiation of the Collector, } \mathrm{W} / \mathrm{m}^{2}\end{array}$

Greek symbols

$\eta_{\mathrm{o}} \quad$ Optical efficiency of the collector, $\%$

$\alpha \quad$ Absorptivity of the absorber copper plate

$\tau \quad$ Transmissivity of glass

\section{REFERENCES}

[1] Schaetzle WJ. Thermal energy storage in aquifers: design and applications. New York: Pergamon; 1980

[2] Schmidt FW. Thermal energy storage and regeneration (series in thermal and fluids engineering). New York: McGraw-Hill; 1981.

[3] Beckmann G, Gill PV. Thermal energy storage: basics-design-applications to power generation and heat supply (course in mathematical physics). Berlin: Springer; 1984.

[4] Garg HP, Mullick SC, Bhargava AK. Solar thermal energy storage. Dordrecht, Holland: Reidel Publishing

[5] Garg HP. Advances in solar technology: collection and storage systems. Dordrechnt: Kluwer Academic Publishers; 1987

[6] Aran sole, Hannag Neumann,Sophia Niedermaier, Luisa F.Cabeza,Elena Palomo. Thermal stability test of sugar alcohols as phase change materials for medium temperature energy storage application.Energy procedia 48(2014) 436-439

[7] Murat kenisarin, Khamid Mahkamov. Solar Energy storage using phase change materials. Renewable and sustainable Energy Reviews 11(2007)1913-1965

[8] Atul Sharma,V.V.Tyagi, C.R.Chen,D.Buddhi. Review on thermal energy storage with phase change materials and application. Renewable and sustainable Energy Reviews13(2009)318-345.

[9] Lane GA. Solar heat storage: latent heat materials, vol. 1. Background and scientific principles. Boca

[10] Lane GA. Solar heat storage: latent heat materials, vol. 2. Technology. Boca Raton, FL: CRC Press; 1985.

[11] Dincer I, Rosen MA. Thermal energy storage: systems and applications. Chichester, England: Wiley; 2002.

[12] Schro"der J, Gawron K. Latent heat storage. Energy Res 1981; 5:103-9.

[13] Liwu Fan,J.M.Khodadadi.Thermal conductivity enhancement of phase change materials for thermal energy storage: A review. Renewable and sustainable Energy Reviews 15(2011)24-46

[14] Kinga pielichowska,Krzysztof pielichowski. Phase change materials for thermal energy storage. Progress in materials science 65(2014)67-123

[15] Mohammed Ali Fazilati, Ali Akbar Alemrajabi.phase Change material for enhancing solar water heater, an 
experimental approach. Energy conservation and managements 71(2013)138-145

[16] Atul Sharma, A.Shukla, C.R. Chen, Tsung -Nan Wu.Development of phase change materials(PCMs) for low temperature energy storage applications. Sustainable Energy technologies and Assessments 7 (2014)1721

[17] Agyenim F, Eames P, Smyth M. A comparison of heat transfer enhancement in medium temperature thermal energy storage heat exchanger using fins and multitubes. ISES Solar World Congress 2007;2726-30.

[18] Kinga pielichowska,Krzysztof pielichowski. Phase change materials for thermal energy storage. Progress in materials science 65(2014)67-123

[19] Weihuan Zhao, Ying Zheng, Joseph C.Sabol, Kemal Tuzla,sudhakar Neti, Alparslan oztekin,John C.Chen. High Temperature calorimetry and use of magnesium chloride for thermal energy storage.Renewable Energy 50(2013)988-993

[20] Muhsin Mazman, Luisa F. Cabeza, Harald Mehling, Miquel Nogues, Hunay Evliya, Halime O. Paksoy. Utilization of phase change materials in solar domestic hot water system, 2009; 34:1639-1643.

[21] Shaokun Song, Lijie Dong, Yang Zhang, Shun Chen, Qi Guo, Sufen Deng, Shuai Si, Chuanxi Xiong. Energy: Lauric acid/intercalated kaolinite as form-stable phase change material for thermal energy storage, 2014; 76:385- 389 .

[22] M.K. Anuar Sharif, A.A. Al-Abidi, S. Mat, K. Sopian, M.H. Ruslan, M.Y. Sulaiman, M.A.M. Rosli. Renewable and Sustainable Energy Reviews: Review of the application of phase change material for heating and domestic hot water systems

[23] A.de Gracia, E.Ora, M.M. Farid, L.F. Cabeza , Thermal analysis of including phase change material in a domestic hot water cylinder, 2011; 31:3938-3945.

[24] Abdul Jabbar N. Khalifa, Raid A. Abdul Jabbar. Energy conversion Management: Conventional Versus Storage domestic solar hot water system: a compar:ative performance study. 2010; 51: 265-270.

[25] Murat M.Kenisarin. High -Temperature phase change materials for thermal energy storage. Renewable and sustainable energy reviews 14 (2010)955-970

[26] V.Saikrishnan, A. Karthikeyan. Thermal behaviour study of phase change material of a latent heatstorage system/ Materials Today: Proceedings 3 (2016) 2518-2524 